\title{
Large testicular adrenal rest tumours in a patient with congenital adrenal hyperplasia
}

\author{
J Rajkanna and S O Oyibo \\ Department of Endocrinology, Peterborough City Hospital, Bretton Gate, Peterborough PE3 9GZ, UK
}

\author{
Correspondence \\ should be addressed \\ to $S$ O Oyibo \\ Email \\ samoyibo@yahoo.co.uk
}

\section{Summary}

Testicular adrenal rest tumours (TARTs) are benign ACTH-dependent tumours that occur in males with congenital adrenal hyperplasia (CAH) and if left untreated can destroy testicular tissue. Corticosteroid suppressive treatment could result in the regression of these testicular tumours. We present a patient with bilateral large TARTs as a consequence of poor compliance to treatment and follow-up for his $\mathrm{CAH}$, who consequently had to have bilateral orchidectomies and prosthesis replacement.

\section{Learning points:}

- TARTs are frequently seen in males with $\mathrm{CAH}$, and can be misdiagnosed as primary testicular cancer.

- Patient compliance to treatment and follow-up are necessary to reduce the risk of testicular damage as a result of TARTs in patients with CAH.

- Boys with CAH should have periodic ultrasonographic screening from before adolescent age for early detection of TARTs.

- Regular monitoring of renin, 17-hydroxyprogesterone and androgens levels is required to assess corticosteroid suppressive treatment.

- Patients with CAH should be offered psychological support and information concerning CAH support groups.

\section{Background}

Congenital adrenal hyperplasia $(\mathrm{CAH})$ is an inherited disorder resulting from the deficiency of enzymes required for synthesis of cortisol in the adrenal gland. The commonest enzyme defect is 21-hydroxylase deficiency and the resultant cortisol deficiency leads to excessive corticotrophin (ACTH) production, which due to bypass effect results in excessive androgen production (1).

Adrenal rest cells first described in 1940 are a group of cells trapped within the developing gonad during foetal development (2). Usually $<5 \mathrm{~mm}$ in size, they are found in the testis and surrounding tissue in $7.5-15 \%$ of new born and in about $1.5 \%$ of adults (3). Testicular adrenal rest tumours (TARTs) are benign ACTH-dependent tumours that have a reported prevalence of up to $94 \%$ in males with CAH (4). We present a patient with bilateral large TARTs as a consequence of poor compliance to treatment and follow-up.

\section{Case presentation}

A 25-year-old male presented to the endocrine clinic in November 2011 with a history of tiredness, reduced libido and bilateral large testicles, which he wanted surgically removed (5).

He had been diagnosed with salt-losing CAH during his antenatal period and commenced on steroid replacement therapy soon after birth. However, he

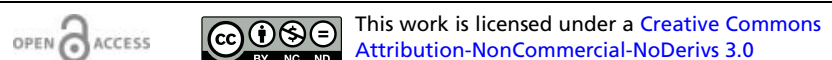
Unported License.
} 
stopped taking all medications in 2000 because of family issues and although his testicles were felt to be lumpy in 2002, further investigation was hampered by poor compliance to treatment and follow-up. He did see the urologist in 2007 but failed to attend follow-up appointments and scans thereafter. He reappeared in the urology clinic in 2010 and again in 2011, after which he was re-referred to the endocrinology department by the urologist in readiness for testosterone replacement therapy after the proposed orchidectomy.

On examination he was well with normal secondary sexual features, but his testicles felt hard and three times the normal size. His serum testosterone level was $50.4 \mathrm{nmol} / \mathrm{l}$. After the baseline investigations (see Table 1) and multiple non-attendances, he finally had bilateral orchidectomy and prosthesis replacement in October 2012. Further follow-up was difficult, and compliance with steroid replacement was again very poor.

\section{Investigation}

Results of baseline and follow-up biochemical investigations are given in Table 1 . The short Synacthen test demonstrated impaired adrenal gland function. The raised serum 17-hydroxyprogesterone, testosterone and dehydroepiandosterone levels were in line with the unsuppressed raised serum ACTH levels. Previous serum tumour markers (alphafetoprotein, lactate dehydrogenase and beta human chorionic gonadotrophin) were normal in 2010 .

An ultrasound scan performed initially in 2010 confirmed large testicles (the right testis measured
$6.2 \times 4.7 \times 2.6 \mathrm{~cm}$, the left testis measured $6.6 \times 3.9 \times$ $3.6 \mathrm{~cm}$ and epididymis could not be visualised).

Pathological examination after orchidectomy demonstrated large testicles measuring $8.5 \times 5 \times 4 \mathrm{~cm}$ in size with no recognisable testicular parenchyma (stage 5) (3). The histology comprised sheets of cells separated by delicate fibrous septa with polygonal tumour cells with abundant oeosinophilic cytoplasm, round, variably sized nuclei and prominent central nucleoli. This histology report is the characteristic of TARTs. The report also mentioned the possible presence of some Reinke crystals.

\section{Treatment}

His initial treatment (restarted in 2011) was hydrocortisone $5 \mathrm{mg}$ twice a day for steroid replacement therapy with the addition of dexamethasone $0.25 \mathrm{mg}$ at bedtime for ACTH suppression.

\section{Outcome and follow-up}

He failed to attend follow-up appointments or do any blood tests after his operation, despite multiple attempts to contact him. However he was discovered again in June 2014 when he was admitted to the Emergency Department with a history of vomiting, dehydration and adrenal insufficiency. He had not been taken dexamethasone, but assured us that he had been taking hydrocortisone tablets. He was discharged on hydrocortisone $10 \mathrm{mg}$ twice a day. We were finally able to obtain some more blood samples (see Table 1) and we await further discussion concerning ACTH suppression and testosterone replacement.

Table 1 Results of blood tests pre- and post-surgery with laboratory reference values.

\begin{tabular}{l}
\hline Biochemical test \\
\hline 17-OH-progesterone \\
Testosterone \\
Corticotrophin (ACTH) \\
Dehydroepiandrosterone \\
Androstenedione \\
Follicle-stimulating hormone \\
Luteinizing hormone \\
Prostate-specific antigen \\
0-min cortisol (pre-Synacthen) \\
30-min cortisol (post-Synacthen) \\
Cortisol 2-h after morning \\
hydrocortisone (10 mg) \\
Sodium \\
Potassium
\end{tabular}

-, Indicates test was not done.

\begin{tabular}{|c|c|}
\hline Normal reference range & Pre-surgery December 2011 \\
\hline$<13 \mathrm{nmol} / \mathrm{l}$ & $>152$ \\
\hline $10-38 \mathrm{nmol} / \mathrm{l}$ & 50.4 \\
\hline $0-50 \mathrm{ng} / \mathrm{l}$ & 139 \\
\hline $1.6-11 \mu \mathrm{mol} / /$ & 12 \\
\hline $1.4-9.1 \mathrm{nmol} / \mathrm{l}$ & - \\
\hline $1-14 \mathrm{U} / \mathrm{I}$ & $<1$ \\
\hline $1-9 \mathrm{U} / \mathrm{l}$ & $<1$ \\
\hline$<2.5 \mu \mathrm{g} / \mathrm{l}$ & 0.27 \\
\hline- & 327 \\
\hline$>550 \mathrm{nmol} / \mathrm{l}$ & 354 \\
\hline- & - \\
\hline $133-146 \mathrm{mmol} / \mathrm{l}$ & 144 \\
\hline $3.5-5.3 \mathrm{mmol} / \mathrm{l}$ & 4.2 \\
\hline
\end{tabular}

\begin{tabular}{c}
\hline Post-surgery May 2013 \\
\hline$>152$ \\
10.8 \\
- \\
- \\
- \\
- \\
- \\
- \\
- \\
- \\
- \\
140 \\
4.3
\end{tabular}

\begin{tabular}{c}
\hline August 2014 \\
\hline 124 \\
3.9 \\
- \\
3.6 \\
21.0 \\
3 \\
2 \\
0.76 \\
- \\
- \\
734 \\
141 \\
4.5 \\
\hline
\end{tabular}




\section{Discussion}

Although TARTs are usually benign, they obstruct the seminiferous tubule, leading to testicular destruction and failure if untreated. There are five stages (stage 1: adrenal rest cells are present within the rete testis; stage 2: hyperplasia and hypertrophy of the rest cells; stage 3: the rest cells compress rete testis; stage 4: induced fibrosis and lymphatic infiltration of testicular perenchyma; stage 5: irreversible damage of testicular perenchyma). They are usually bilateral, with a reported prevalence of up to $94 \%$ in males with $\mathrm{CAH}$ and are ACTH dependant. As a result of 21-hydroxylase deficiency these patients have high serum ACTH, 17-hydroxyprogesterone and androgens. Intensive corticosteroid therapy, which suppresses ACTH secretion, often leads to a reduction in size of these tumours (4) (6). If glucocorticoid treatment is ineffective, testis-sparing orchidectomy is recommended to save unaffected testicular parenchyma (7).

It can be difficult to distinguish between TARTs and Leydig cell tumours of the testis and there have been reports of the coexistence of both conditions in patients with CAH (8). However, Leydig cell tumours are rarely bilateral and are not corticosteroid-responsive like TARTs. In addition, the lack of malignant features on histology after many years of diagnosis makes Leydig cell tumour less likely. Our patient did have very high serum testosterone levels, which has been reported as more suggestive of the presence of a Leydig cell tumours (8). There was also a histological suspicion of the presence of some Reinke crystals, which are cytoplasmic rod-like crystalloids particles found in $30-46 \%$ of the Leydig cell tumours. The possible presence of a few of these crystals in our case could indicate the co-existence of benign Leydig cell tumours (9). In addition, the fall in serum testosterone back to the lower end of normal reference range post-surgery does potentiate the suspicion of the possible co-existence of functioning Leydig cells. Unfortunately, because of the poor followup the testosterone issue could not be further assessed. In addition, the steroid-responsiveness of TARTs could not be assessed in this patient with large destructive tumours.

For patients with stage 4 TARTs, where medical therapy (corticosteroid suppression) has failed to result in tumour regression, testis-sparing surgery is the treatment of choice to prevent progression to stage 5 when severe obstructive fibrosis of the testicular parenchyma ensues (3) (7). Testicular biopsy to assess the presence of healthy testicular parenchyma should precede surgery. Our patient had already reached stage 5 with very large testicular masses which were causing discomfort, both physically and psychologically. The patient opted for bilateral total orchidectomies and replacement prosthesis. Pathological examination revealed the absence of any testicular parenchyma.

There is bound to be psychosocial issues associated with the affectation of testicular anatomy and function in patients with $\mathrm{CAH}$ and TARTs. These can range from depression to impairment of sexual well-being (10). A population-based survey of patients with $\mathrm{CAH}$ in Norway demonstrated that they had significantly impaired subjective health status as measured by the SF-36 questionnaire, and a higher proportion of the patients than the general population receiving working disability benefit (11). These could be major contributory factors to this patient's poor compliance with treatment and follow-up during childhood and adolescence. The importance of early introduction of patients with $\mathrm{CAH}$ to a child psychologist and available CAH support groups cannot be overemphasised.

In conclusion, we have described a patient with $\mathrm{CAH}$ who developed large TARTs as a result of poor compliance to medical treatment and follow-up, and subsequently required bilateral orchidectomies and replacement prosthesis. We reiterate that adequate medical treatment, regular outpatient follow-up and psychosocial support are required by patients with CAH to prevent acute and chronic, physical and psychological complications.

Declaration of interest

The authors declare that there is no conflict of interest that could be perceived as prejudicing the impartiality of the research reported.

\section{Funding}

This research did not receive any specific grant from any funding agency in the public, commercial or not-for-profit sector.

\section{Patient consent}

Written informed consent has been obtained from the patient for publication of the submitted article and any accompanying images. The signed copy of the consent form has been provided.

\section{Author contribution statement}

The first author (Dr J Rajkanna) and the second author ( $\mathrm{Dr}$ S O Oyibo) identified the patient, wrote up the case and presented the case at the Society for Endocrinology BES 2014 Meeting. Dr S O Oyibo is also the named physician of the patient.

\section{References}

1 Speiser PW \& White PC 2003 Congenital adrenal hyperplasia. New England Journal of Medicine 349 776-788. (doi:10.1056/NEJMra021561) 
2 Wilkins L, Fleishmann W \& Howard JE 1940 Macrogenitosomia precox associated with hyperplasia of the androgenic tissue of the adrenal and death from corticoadrenal insufficiency. Endocrinology 26 385-395. (doi:10.1210/endo-26-3-385)

3 Claahsen-van der Grinten HL, Hermus ARM \& Otten BJ 2009 Testicular adrenal rest tumours in congenital adrenal hyperplasia. International Journal of Pediatric Endocrinology . 624823 . (http://www.ijpeonline.com/ content/2009/1/624823).

4 Claahsen-van der Grinten HL, Sweep FC, Blickman JG, Hermus AR \& Otten BJ 2007 Prevalence of testicular adrenal rest tumours in male children with congenital adrenal hyperplasia due to 21-hydroxylase deficiency. European Journal of Endocrinology 157 339-344. (doi:10.1530/EJE-07-0201)

5 Rajkanna J \& Oyibo S 2014 Large testicular adrenal rest tumours in a patient with congenital adrenal hyperplasia: a consequence of poor drug compliance. Endocrine Abstracts 34 P55. (doi:10.1530/ endoabs.34.P55)

6 Cabrera MS, Vogiatzi MG \& New MI 2001 Long term outcome in adult males with classical congenital adrenal hyperplasia. Journal of Clinical Endocrinology and Metabolism 86 3070-3078. (doi:10.1210/jcem. 86.7.7668)
7 Tiryaki T, Aycan Z, Hucumenoglu S \& Atayurt H 2006 Testis sparing surgery for steroid unresponsive testicular tumours of the congenital adrenal hyperplasia. Pediatric Surgery International 21 853-855. (doi:10.1007/s00383-005-1547-x)

8 Charfi N, Kamoun M, Feki Mnif M, Mseddi N, Mnif F, Kallel N, Naceur BB, Rekik N, Fourati H, Daoud E et al 2012 Leydig cell tumor associated with testicular adrenal rest tumors in a patient with congenital adrenal hyperplasia due to 11-hydroxylase deficiency. Case Reports in Urology 2012 5. (http://dx.doi.org/10.1155/2012/648643)

9 Boscolo-Berto R, Bonandini E, Gardiman M, De Marco V, Lafrate M \& Novara G 2009 Leydig cell tumour or adrenal rest tumour of the testes? A case of uncertain diagnosis Journal of Andrological Sciences 16 64-68.

10 Ogilvie CM, Crouch NS, Rumsby G, Creighton SM, Liao LM \& Conway GS 2006 Congenital adrenal hyperplasia in adults: a review of the medical, surgical and psychological issues. Clinical Endocrinology 64 2-11. (doi:10.1111/j.1365-2265.2005.02410.x)

11 Nermoen I, Husebye ES, Svartberg J \& Lovas K 2010 Subjective health status in men and women with congenital adrenal hyperplasia: a population-based survey in Norway. European Journal of Endocrinology 163 453-459. (doi:10.1530/EJE-10-0284)

Received in final form 22 December 2014

Accepted 14 January 2015 